\title{
Dactylosporangium vinaceum sp. nov.
}

\author{
TAKASHI SHOMURA,* JUNKO YOSHIDA, SHINJI MIYADOH, TATSUO ITO, AND TARO NIIDA \\ Central Research Laboratories, Meiji Seika Kaisha, Ltd., 760, Morooka-cho, Kohoku-ku, Yokohama 222, \\ Japan
}

\begin{abstract}
A newly isolated actinomycete, which was recovered from a soil sample in Japan, has been found to possess finger-shaped sporangia, motile spores, and other characteristics of members of the genus Dactylosporangium. This organism produces dactimicin, a pseudodisaccharide antibiotic elaborated by at least one other species of Dactylosporangium, and differs significantly from the three previously described species of Dactylosporangium in its production of a winecolored pigment, which not only occurs in vegetative mycelium but is observed as an extracellular, diffusible substance in agar medium used to cultivate the organism. On the basis of these and other differences, we propose that strains with these characteristics be designated as a new species, Dactylosporangium vinaceum. Strain SF-2127 (= IFO 14181) is the type strain.
\end{abstract}

During a screening program for new antibiotic producers from uncommon genera of the order Actinomycetales Buchanan 1917, we isolated two rare actinomycetes (strains SF-2052 ${ }^{\mathrm{T}}$ [type strain] and SF-2127 $7^{\mathrm{T}}$ ) which produce a new pseudodisaccharide antibiotic, dactimicin $(9$, 13).

These two strains are very similar in their characteristics and were found to belong to the genus Dactylosporangium Thiemann, Pagani and Beretta (15) on the basis of their characteristic morphology (i.e., formation of finger-shaped sporangia arising directly from the vegetative mycelium and three or four zoospores arranged in a single straight row inside a sporangium). Recently, it has been reported that strain SF$2052^{\mathrm{T}}$ differs significantly from other established species in the genus Dactylsporangium, and this strain was designated the type strain of a newly proposed species, Dactylosporangium matsuzakiense (13). Upon further study, strain SF- $2127^{\mathrm{T}}$ has been found to be distinct from other species of Dactylosporangium in a number of basic properties, particularly in the wine color of its vegetative mycelium and in the production of a diffusible pigment.

In this report, we compare strain $\mathrm{SF}-2127^{\mathrm{T}}$ with previously recognized species of Dactylosporangium, including Dactylosporangium aurantiacum Thiemann et al. 1967 (15), Dactylosporangium thailandense Thiemann 1970 (14), and D. matsuzakiense Shomura et al. (13).

\section{MATERIALS AND METHODS}

Actinomycetales strains. Strain SF-2127 ${ }^{\mathrm{T}}$ was isolated in August 1979 in our laboratory from a soil sample collected at Sekigahara, Gifu Prefecture, Japan. For comparative purposes, we studied the following strains: D. aurantiacum strain KCC A-0083 ${ }^{\mathrm{T}}$ ATCC $23491^{\mathrm{T}}$ ) and D. thailandense strain KCC A$0084^{\mathrm{T}}$ (= ATCC $23490^{\mathrm{T}}$ ), both of which were obtained from the culture collection of the Kaken Chemical Co., Ltd., Tokyo, Japan; and D. matsuzakiense strain SF-2052 ${ }^{\mathrm{T}}$ (= ATCC $31570^{\mathrm{T}}$ ) from our collection, which was isolated in May 1977 in our laboratory from a soil sample collected at Matsuzaki-cho, Izu Peninsula, Japan (13).

Media. Washed cells were inoculated onto the following media: ISP media 2 to 7 (12); sucrose-nitrate agar; glucose-asparagine agar; nutrient agar; Bennett agar; potato plug and calcium malate agar of Waksman (16); and Hickey-Tresner agar (3). Inoculated plates were incubated at $28^{\circ} \mathrm{C}$.

Morphological characterization. The morphologies of the sporangia and spores of the strains grown on sucrose-nitrate agar and oatmeal agar (ISP medium 3) were studied by both light microscopy and electron microscopy. For scanning electron microscopy, an agar block containing numerous sporangia was fixed in $2.5 \%$ glutaraldehyde. The block was then gradually dehydrated with increasing amounts of acetone and finally dried by the critical point method (1). Each specimen was coated with evaporated gold and examined with a scanning electron microscope (model JEM 100C-ASID; Japan Electron Optics Laboratory Co., Ltd.).

Cultural characterization. The cultural characteristics of the strains on various media were observed after 14 days of incubation at $28^{\circ} \mathrm{C}$. Color determinations were made by comparing the cultures with color chips from the Color Harmony Manual (4).

Physiological characterization. The media and procedures used for physiological characterization were similar to those outlined by Waksman (16) and Shirling and Gottlieb (12). The temperature range for growth was determined on ISP medium $4 . \mathrm{NaCl}$ tolerance was measured on Luedemann agar medium (7) containing different concentrations of $\mathrm{NaCl}(0,1.5,3,5$, and $7 \%)$. Carbon utilization tests were performed in the basal medium of Luedemann and Brodsky $(8)_{2}$, since strain 


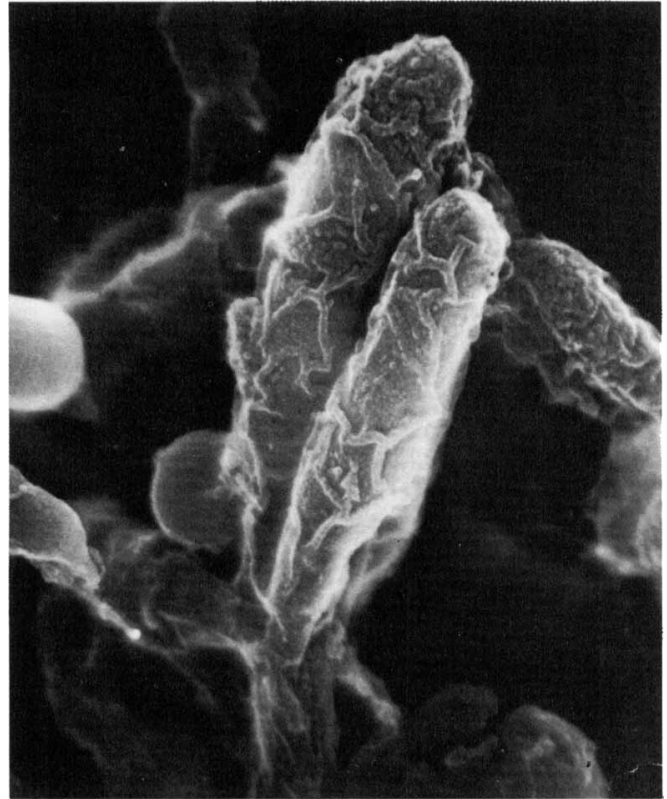

FIG. 1. Finger-shaped sporangia of strain SF-2127 ${ }^{\mathrm{T}}$ on sucrose-nitrate agar, as observed with a scanning electron microscope. The organism was incubated at $28^{\circ} \mathrm{C}$ for 14 days. $\times 15,000$.

SF $-2127^{\mathrm{T}}$ did not grow on the medium described by Thiemann et al. (15) or that described by Pridham and Gottlieb (10).

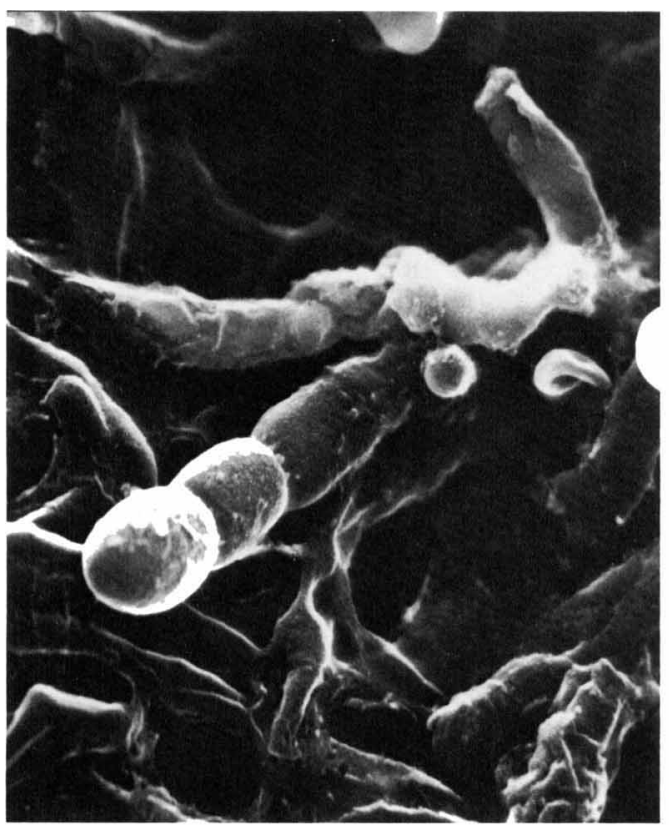

FIG. 2. Naked sporangiospores of strain SF-2127 ${ }^{\mathrm{T}}$ on oatmeal agar (ISP medium 3), as observed with a scanning electron microscope. The organism was incubated at $28^{\circ} \mathrm{C}$ for 14 days. $\times 15,000$.
Cell wall analysis. Cell walls were analyzed by the procedure of Becker et al. (2), and whole cells were analyzed by the method of Lechevalier (5).

\section{RESULTS}

Morphological characteristics. Colonies of strain $\mathrm{SF}-2127^{\mathrm{T}}$ were compact, tough, and somewhat leathery. The vegetative mycelium was long, irregularly branched, twisted, and 0.5 to $0.7 \mu \mathrm{m}$ in diameter penetrated the agar. Fragmentation of hyphae usually did not occur on agar or in submerged growth in liquid cultures. Aerial mycelium was not usually observed on agar cultures; however, a slight trace of rudimentary hyphae developed on oatmeal agar (ISP medium 3). Strain SF-2127 ${ }^{\mathrm{T}}$ produced fingershaped sporangia. Sporangia were occasionally apparent when the strain was grown on sucrosenitrate agar and oatmeal agar, less apparent on inorganic salts-starch agar (ISP medium 4) and calcium malate agar, and rarely apparent on glycerol-asparagine agar (ISP medium 5) or yeast extract-malt extract agar (ISP medium 2); they appeared after 5 to 15 days of incubation at $28^{\circ} \mathrm{C}$ and occurred singly or in tufts on the surface of agar media. Finger-shaped sporangia ( 0.8 to 1.1 by 3.0 to $5.5 \mu \mathrm{m}$ ) formed on short sporangiophores $(0.5$ to $1.5 \mu \mathrm{m}$ long $)$ which emerged directly from the vegetative hyphae. Scanning electron microscopy revealed fingershaped sporangia with wrinkled envelopes (Fig.

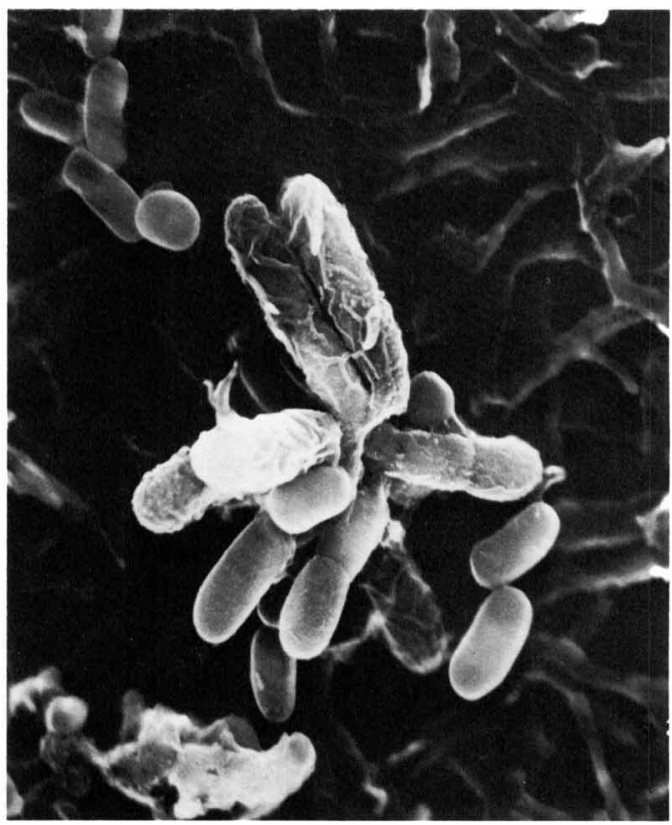

FIG. 3. Sporangia and sporangiospores of strain SF-2127 $7^{\mathrm{T}}$ on oatmeal agar (ISP medium 3), as observed with a scanning electron microscope. The organism was incubated at $28^{\circ} \mathrm{C}$ for 14 days. $\times 7,500$. 
TABLE 1. Cultural characteristics of strain SF-2127

\begin{tabular}{|c|c|c|c|c|}
\hline Medium & Growth & Reverse color ${ }^{a}$ & Sporangia & Soluble pigment ${ }^{a}$ \\
\hline Sucrose-nitrate agar & Good & Light wine $(71 / 2$ ne) & Moderate & Cherry (7 lc) \\
\hline Glucose-asparagine agar & Good & Dark wine $(71 / 2 \mathrm{pi})$ & None & Wine $(71 / 2 \mathrm{pg})$ \\
\hline $\begin{array}{l}\text { Glycerol-asparagine agar (ISP } \\
\text { medium 5) }\end{array}$ & Poor & Apricot (4 ia) & Very poor & $\begin{array}{l}\text { None or very light } \\
\text { wine }\end{array}$ \\
\hline $\begin{array}{l}\text { Inorganic salts-starch agar } \\
\text { (ISP medium 4) }\end{array}$ & Good & Old wine $(71 / 2 \mathrm{ng})$ & $\begin{array}{l}\text { Poor or } \\
\text { moderate }\end{array}$ & Light wine $(71 / 2 \mathrm{ne})$ \\
\hline Oatmeal agar (ISP medium 3) & Good & Wine $(7 \mathrm{pg})$ & Moderate & Wine red $(71 / 2 \mathrm{pe})$ \\
\hline $\begin{array}{l}\text { Yeast extract-malt extract agar } \\
\text { (ISP medium 2) }\end{array}$ & Moderate & Ebony brown ( $8 \mathrm{pn})$ & Very poor & Deep red $(8 \mathrm{pc})$ \\
\hline Tyrosine agar (ISP medium 7) & Poor & Wine $(71 / 2 \mathrm{pg})$ & $\begin{array}{l}\text { None or } \\
\text { very poor }\end{array}$ & Deep red $(71 / 2 \mathrm{pc})$ \\
\hline Nutrient agar & Poor & Wine $(71 / 2 \mathrm{pg})$ & None & Light wine $(71 / 2$ ne $)$ \\
\hline Bennett agar & Good & Ebony brown ( $8 \mathrm{pn}$ ) & None & Wine red $(71 / 2 \mathrm{pe})$ \\
\hline Hickey-Tresner agar & Good & Dark wine $(71 / 2 \mathrm{pi})$ & None & Wine red $(71 / 2$ pe $)$ \\
\hline Calcium malate agar & Poor & Wine $(7 \mathrm{pg})$ & Poor & Rose wine $(7 \mathrm{le})$ \\
\hline Potato plug & Moderate & Redwood (6 ne) & None & Rose wine $(8 \mathrm{le})$ \\
\hline
\end{tabular}

${ }^{a}$ For explanation of color designations, see reference 4.

1). Naked sporangiospores, which appeared shortly after the sporangial membranes broke, were also observed (Fig. 2 and 3). Each sporangium contained three spores arranged in a single row. Sporangia and newly emerged naked spores within a tuft were also apparent (Fig. 3). Spores were cylindrical (some were oblong) and measured 0.6 to 0.9 by 0.9 to $1.8 \mu \mathrm{m}$.

Spore release was observed by flooding the surfaces of sporangium-containing cultures with sterile water or soil extract solution. After sporangium dehiscence occurred, the spores were clearly motile, but there was a time lag of about $30 \mathrm{~min}$ before they became highly motile. Although motile spores were vigorous swimmers, flagellum staining was not successful.

Formation of globose bodies, which have been described by Thiemann et al. (15) and Sharples and Williams (11), was observed on both glucose-asparagine agar and nutrient agar.

Cultural characteristics. Table 1 summarizes the amounts of growth, the formation of sporan- gia, the colors of reverse vegetative mycelia, and the diffusible pigments produced by strain SF- $2127^{\mathrm{T}}$ on various media. Strain SF-2127 ${ }^{\mathrm{T}}$ was clearly distinct from the other strains studied in that it elaborated a diffusible pigment. The color of this pigment ranged from wine to deep red; vegetative mycelium color varied from wine to ebony brown, depending on the amount of diffusion of extracellular pigment into the agar. Pigment in the vegetative mycelia or the diffusible pigment was not sensitive to $\mathrm{pH}$ changes, since pigment color was stable when cultures were exposed to either $0.05 \mathrm{~N} \mathrm{HCl}$ or $0.05 \mathrm{~N} \mathrm{NaOH}$.

Physiological characteristics. The results of a comparative study of the physiological characteristics of strain SF- $2127^{\mathrm{T}}$ with those of the type strains of other established species of Dactylosporangium are summarized in Table 2. All strains hydrolyzed starch, showed strong utilization of D-glucose, D-xylose, D-mannitol, L-arabinose, and L-rhamnose, failed to utilize raffinose, i-inositol, or glycerol, and did not produce

TABLE 2. Comparison of strain SF-2127 ${ }^{\mathrm{T}}$ with reference strains of three Dactylosporangium species ${ }^{a}$

\begin{tabular}{|c|c|c|c|c|}
\hline Test & Strain SF-2127 & 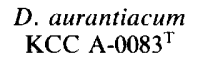 & 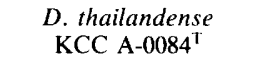 & $\begin{array}{l}\text { D. matsuzakiense } \\
\mathrm{SF}-2052^{\mathrm{T}}\end{array}$ \\
\hline Color of reverse & Wine to brown & Orange & Orange to brown & Orange \\
\hline Diffusible pigment & Wine to deep red & None & $\begin{array}{l}\text { Sometimes, amber } \\
\text { or brown }\end{array}$ & $\begin{array}{l}\text { Sometimes, light } \\
\text { brownish pink }\end{array}$ \\
\hline Liquefaction of gelatin & Positive & Positive & Negative & Negative \\
\hline Reduction of nitrate & Negative & Positive & Negative & Negative \\
\hline Peptonization of milk & Positive & Negative & Negative & Negative \\
\hline Coagulation of milk & Positive & Negative & Negative & Negative \\
\hline Growth at $42^{\circ} \mathrm{C}$ & None & Poor & None & Very poor \\
\hline $\mathrm{NaCl}$ tolerance & $3 \%$ & $3 \%$ & $1.5 \%$ & $<1.5 \%$ \\
\hline \multicolumn{5}{|l|}{ Utilization of: } \\
\hline D-Fructose & ++ & + & ++ & + \\
\hline Sucrose & ++ & + & ++ & ++ \\
\hline
\end{tabular}

${ }^{a}$ Symbols: ++ , strongly positive utilization; + , positive utilization. 
melanoid pigment. The optimum temperature for growth of all strains was between 25 and $37^{\circ} \mathrm{C}$.

Cell wall analysis. An analysis of strain SF$2127^{\mathrm{T}}$ cell wall hydrolysates by paper chromatography demonstrated the presence of 3-hydroxydiaminopimelic acid, which gave the same greenish color with ninhydrin reagent as diaminopimelic acid but moved more slowly than meso-diaminopimelic acid. Furthermore, cell walls also contained large amounts of muramic acid, glutamic acid, glycine, and alanine and a trace of meso-diaminopimelic acid. Xylose and a trace of arabinose were detected as the sugars in the whole-cell hydrolysates. Thus, strain SF$2127^{\mathrm{T}}$ can be considered to have type II cell walls and whole-cell sugar pattern $D$ in the classification scheme of Lechevalier and Lechevalier (6).

\section{DISCUSSION}

The formation of finger-shaped sporangia containing motile spores, the absence of true aerial mycelium, and type II cell walls place strain SF$2127^{\mathrm{T}}$ in the genus Dactylosporangium Thiemann, Pagani and Beretta (15). Since Thiemann et al. described $D$. aurantiacum (15) and $D$. thailandense $(14,15)$ in 1967 and 1970, respectively, only one additional species, D. matsuzakiense (13), has been reported. We compared cultures of strain SF-2127 $7^{\mathrm{T}}$ directly with the type strains of the three previously described species to assess differences in morphology and cultural and physiological properties. No outstanding differences in morphology were apparent among the type strains of the three previously described species and strain $\mathrm{SF}-2127^{\mathrm{T}}$, regardless of whether sporangia or spores were compared. The results of studies of the physiological properties of strain $S F-2127^{\mathrm{T}}$ indicated that this strain differed slightly in several physiological markers used to characterize actinomycetes, although there was good agreement in the carbon utilization patterns of the strains tested when comparisons were made on the basal medium of Luedemann and Brodsky (8).

However, strain SF-2127 $7^{\mathrm{T}}$ clearly does differ from the three other species in its production of a wine to deep red diffusible pigment, and this pigment was produced on all agar media used in our study. To our knowledge, production of this type of extracellular pigment by Dactylosporangium strains is unusual.

D. thailandense strain ATCC $23490^{\mathrm{T}}$ produces an amber or brown diffusible pigment on selected media, such as Hickey- and Tresner agar, yeast extract-malt extract agar, and sucrosenitrate agar $(13,15)$, whereas $D$. matsuzakiense strain $\mathrm{SF}-2052^{\mathrm{T}}$ produces a light brownish pink diffusible pigment only on tyrosine agar (ISP medium 7) (13). No obvious diffusible pigment has been described for $D$. aurantiacum strain ATCC $23491^{\mathrm{T}}$.

In view of the characteristics described above, we believe that strain $\mathrm{SF}-2127^{\mathrm{T}}$ warrants consideration as a new species in the genus Dactylosporangium. We hereby propose the name Dactylosporangium vinaceum sp. nov. (vi.n' ce.um. L. neut. adj. vinaceum wine colored, referring to the color of the diffusible pigment produced) for strains with the properties described above. Strain SF-2127 is the type strain of $D$. vinaceum. A culture of this strain has been deposited in the Institute for Fermentation, Osaka, Japan, under the number IFO 14181 .

\section{ACKNOWLEDGMENT}

We thank A. Seino of Kaken Chemical Co., Ltd., for providing the reference strains of $D$. aurantiacum and $D$. thailandense.

\section{LITERATURE CITED}

1. Anderson, T. F. 1951. Techniques for the preservation of three-dimensional structure in preparing specimens for the electron microscope. Trans. N. Y. Acad. Sci. Ser, 2 13:130-134.

2. Becker, B., M. P. Lechevalier, and H. A. Lechevalier. 1965. Chemical composition of cell-wall preparations from strains of various form-genera of aerobic actinomycetes. Appl. Microbiol. 13:236-243.

3. Hickey, R. J., and H. D. Tresner. 1952. A cobalt-containing medium for sporulation of Streptomyces species. J. Bacteriol. 64:891-892.

4. Jacobson, E., W. C. Grauville, and C. E. Fogs. 1958. Color harmony manual, 4 th ed. Container Corporation of America, Chicago.

5. Lechevalier, M. P. 1968. Identification of aerobic actinomycetes of clinical importance. J. Lab. Clin. Med. 71:934944.

6. Lechevalier, M. P., and H. Lechevalier. 1970. Chemical composition as a criterion in the classification of aerobic actinomycetes. Int. J. Syst. Bacteriol. 20:435-443.

7. Luedemann, G. M. 1971. Micromonospora purpureochromogenes (Waksman and Curtis 1916) comb. nov. (subjective synonym: Micromonospora fusca Jensen 1932). Int. J. Syst. Bacteriol. 21:240-247.

8. Luedemann, G. M., and B. C. Brodsky. 1964. Taxonomy of gentamicin-producing Micromonospora, p. 116-124. Antimicrob. Agents Chemother. 1963.

9. Ohba, K., T. Tsuruoka, K. Mizutani, N. Kato, S. Omoto, N. Ezaki, S. Inouye, T. Niida, and K. Watanabe. 1981. Studies on a new aminoglycoside antibiotic, dactimicin. II. Isolation, structure and chemical degradation. J. Antibiot. 34:1090-1100.

10. Pridham, T. G., and D. Gottlieb. 1948. The utilization of carbon compounds by some Actinomycetales as an aid for species determination. J. Bacteriol. 56:107-114.

11. Sharples, G. P., and S. T. Williams. 1974. Fine structure of the globose bodies of Dactylosporangium thailandense (Actinomycetales). J. Gen. Microbiol. 84:219-222.

12. Shirling, E. B., and D. Gottlieb. 1966. Methods for characterization of Streptomyces species. Int. J. Syst. Bacteriol. 16:313-340

13. Shomura, T., M. Kojima, J. Yoshida, M. Ito, S. Amano, K. Totsugawa, T. Niwa, S. Inouye, T. Ito, and T. Niida. 1980. Studies on a new aminoglycoside antibiotic, dacti- 
micin. I. Producing organism and fermentation. J. Antibiot. 33:924-930.

14. Thiemann, J. E. 1970. Dactylosporangium thailandensis should be $D$. thailandense. Int. J. Syst. Bacteriol. 20:59.

15. Thiemann, J. E., H. Pagani, and G. Beretta. 1967. A new genus of the Actinoplanaceae: Dactylosporangium, gen. nov. Arch. Mikrobiol. 58:42-52.

16. Waksman, S. A. 1961 . The actinomycetes, vol. 2. Classification, identification and description of genera and species. The Williams \& Wilkins Co., Baltimore. 